\title{
Transdental ışık uygulamasının kompozit rezinlerin polimerizasyonu üzerine etkisi
}

\author{
Oya Bala', Hacer Deniz Arısu', insan Yıkılgan¹, Nazlı Özge Yanar ${ }^{1}$, Şükrü Kalaycı²
}

Selcuk Dental Journal, 2014; 3: 108-114

Bașvuru Tarihi: 19 Kasım 2014 Yayına Kabul Tarihi: 25 Kasım 2014

\section{Effect of transdental light exposure on polymerization of composite resin}

Background: To evaluate the effect of transdental light curing over different thickness dentin discs, on polymerization of resin composites with FTIR spectroscopy and Vickers microhardness testing device.

Methods: 1,2 and $3 \mathrm{~mm}$ diameter dentin discs were prepared from the buccal surface of non- carious third molars. $5 \mathrm{~mm}$ diameter and $2 \mathrm{~mm}$ depth composite samples were prepared on teflon mold (Clearfill Majesty Esthetic) and a thermocouple connected digital thermometer placed into the composite resins. Dentin discs were placed different thickness as group 1: $1 \mathrm{~mm}$, group 2: $2 \mathrm{~mm}$, group 3: $3 \mathrm{~mm}$. Then resin composites were placed and light cured 40s with LED curing units over the dentin disks. Control group samples were light cured over a $10 \mathrm{~mm}$ thickness glass plate. Each groups included 10 samples. After polymerization; the increase of heat was recorded with digital thermometer. Five of the samples were used for microhardness test, remaining 5 samples were used for measurement of degree of convertion. DC was evaluated with FTIR spectroscopy, microhardness was measured with Vickers microhardness testing device. ANOVA and Tukey test were used for the statistical analysis.

Results: For increase of heat in the composite materials there were significant differences between groups during the polymerization. Group 1 (95.16\%) showed highest DC values, the lowest values were obtained in group 3. Group 1 exhibited the highest microhardness values at the both top and bottom side.

Conclusion: According to this study results, it can be concluded that the dentin thickness cover the composite resins has an effect on polymerization of composite resins.

\section{KEY WORDS}

Composite resin, degree of convertion, surface hardness, transdental light exposure
Polimerizasyon büzülmesi; kompozit rezinlerde polimerizasyon reaksiyonu ile meydana gelen hacimsel küçülme olarak tanımlanır. Polimerizasyon büzülmesi, polimerizasyon öncesi kompozit rezinin yapısında bulunan monomerlerin arasında bulunan zayıf Van der Walls bağlarının daha güçlü olan kovalent bağlara dönüşmesi ile meydana gelmektedir. Polimerizasyon büzülmesi, kompozit restorasyonların klinik başarısını etkileyen önemli bir faktördür. Marjinal uyumsuzluklar, postoperatif hassasiyet, diş-kompozit rezin ara yüzünde bağlantı kayıpları gibi birçok klinik problemin temelinde polimerizasyon büzülmesi yatmaktadır (Loguercio ve ark 2004, Braga ve Ferracane 2002).

Polimerizasyon büzülmesi tamamen engellenemese de inorganik doldurucu miktarının artırıması, monomer tipinin değiştirilmesi ve monomer/ko monomer oranının artırıması gibi yapısal değişiklikler ile büzülme oranı azaltılabilir (Anttila ve ark 2008, Atai ve Watts 2006, Charton ve ark 2007, Sun ve Lin-Gibson 2008, Ellakwa ve ark 2007). Klinik uygulamalarda ise kompozit rezinin tabakalama tekniği ile yerleştirilmesi, kaide materyali kullanımı, uygulama öncesi kompozit rezinin soğutulması, LED ışık cihazlarının kullanımı ve farklı ışık uygulama teknikleri gibi yaklaşımlar ile polimerizasyon büzülmesi kontrol edilebilir (Lee ve ark 2007, Park ve ark 2008, Ferracane 2008, Visvanathan ve ark 2007, Tarle ve ark 2006, Pfeifer ve ark 2006, Cunha ve ark 2008).

Polimerizasyon büzülmesini azaltmak ve/veya oluşmasını engellemek için softstart, pulse-delay ve transdental gibi farklı

\footnotetext{
${ }^{1}$ Gazi Üniversitesi Diş Hekimliği Fakültesi, Diş Hastalıkları ve Tedavisi Anabilim Dalı, Ankara, Türkiye

${ }^{2}$ Gazi Üniversitesi Fen Fakültesi, Kimya Anabilim Dalı, Ankara, Türkiye
} 
ışı uygulama tekniklerinin kullanılması tavsiye edilmektedir (Visvanathan ve ark 2007, Tarle ve ark 2006, Pfeifer ve ark 2006, Cunha ve ark 2008). Softstart ışık uygulama tekniğinde; düşük ışık yoğunluğu ile başlayan polimerizasyon yüksek ışık yoğunluğu ile tamamlanmaktadır. Pulse-delay ışık uygulama tekniğinde, kısa süreli yüksek yoğunlulukta ışık uygulanarak bir süre beklenir. Sonrasında uzun süreli yüksek yoğunlukta ışı uygulaması yapılarak polimerizasyon işlemi tamamlanır. Transdental ışık uygulamasında ise diş dokularının üzerinden ışık uygulanarak polimerizasyon işlemi yapılır (Visvanathan ve ark 2007).

Geleneksel ışık uygulama tekniğinden farklı ışık uygulama tekniklerinin kullanımının polimerizasyon büzülmesini azaltma etkisinin yanısıra kompozit rezinin ideal bir şekilde polimerize olmasına da katkısı bulunmaktadır. Yetersiz polimerizasyonun, kompozit rezinin fiziksel ve biyolojik özelliklerinde önemli ölçüde azalmaya neden olduğu birçok çalışmada rapor edilmiştir (Sharafeddin ve Sharifi 2013, Lohbauer ve ark 2005, Moharamzadeh ve ark 2007, Darmani ve ark 2007). Fiziksel olarak; yüzey sertliğinde azalma, bağlantı kayıpları, düşük aşınma direnci ve kırılganlık karşımıza çıkan önemli problemlerdendir (Sharafeddin ve Sharifi 2013, Lohbauer ve ark 2005). Biyolojik olarak ise pulpal ve gingival iritasyon yetersiz polimerizasyonun kaçınılmaz sonuçlarıdır (Moharamzadeh ve ark 2007, Darmani ve ark 2007). Bu nedenle polimerizasyon tekniklerinin değerlendirildiği çalışmalarda polimerizasyon miktarının da değerlendirilmesi gerekmektedir.

$\mathrm{Bu}$ çalışmanın amacı, farklı kalınlıklarda dentin disklerinin üzerinden transdental ışık uygulanmasının kompozit rezinin polimerizasyonu üzerine etkisini Fourier Transform Infrared Spectroscopy (FTIR) ve Vickers mikrosertlik testleri ile incelemektir.

\section{GEREÇ ve YÖNTEM}

Çalışmaya başlamadan önce çürüksüz alt 3. büyük azı dişlerin bukkal yüzeylerinden yavaş dönen kesme aleti ile su soğutması altında 1, 2 ve $3 \mathrm{~mm}$ kalınlıkta dentin diskleri hazırlandı.

\section{Örneklerin hazırlanması}

$5 \mathrm{~mm}$ çapında $2 \mathrm{~mm}$ derinliğinde, kompozit rezin (Clearfil Majesty Esthetic, Kuraray, Osaka Japonya) ile doldurulmuş teflon kalıpların üzerine Grup 1'de 1 $\mathrm{mm}$ kalınlığında dentin diski, Grup 2'de $2 \mathrm{~mm}$ kalınlığında dentin diski ve Grup 3'de $3 \mathrm{~mm}$ kalınlığında dentin diski yerleştirildi. Polimerizasyon esnasında kompozit rezin içerisinde ısı artışını tespit edebilmek amacıyla kompozit materyalin içerisine bir ucu dijital termometreye bağlı ısıl çift yerleştirildi. Daha sonra dentin disklerinin üzerinden LED ışık cihazı (Hilux, Benlioğlu, Ankara, Türkiye) ile 40 sn ışık uygulanarak kompozit rezin örnekleri polimerize edildi. Kontrol grubunda ise kompozit rezinin üzerine $10 \mathrm{~mm}$ kalınlığında bir cam yerleştirildi ve kompozit rezin bu cam üzerinden polimerize edildi. Polimerizasyon sırasında dijital termometre ile tespit edilen ısı artışı her örnek için kaydedildi.

Her bir grup için toplam 10 adet örnek hazırlandı. Bu örneklerin beş adedi ise FTIR ile polimerizasyon miktarının tespit edilmesi, diğer beş adedi ise yüzey sertlik ölçümlerinin yapılması amacıyla kullanıldı.

\section{Polimerizasyon miktarının hesaplanması}

Çalışmada incelenen grupların polimerizasyon miktarı FTIR'de, potasyum bromür (KBr) tablet tekniği kullanılarak incelendi. Bu amaçla hazırlanan örnekler toz haline getirildikten sonra $\mathrm{KBr}$ ile karıştırılarak tabletler elde edildi. Daha sonra bu tabletler spektroskopi cihazının örnek okuma bölümüne yerleştirilerek her örneğin spektroskopik grafikleri elde edildi. Polimerize edilmeyen kompozit rezinden de aynı şartlarda tabletler hazırlanarak spektroskopik grafiler çekildi. Elde edilen grafikler üzerinde alifatik karbon çift bağlarının absorbans bandları $1640 \mathrm{~cm}-1$ 'de, aromatik karbon çift bağlarının absorbans bandları 1610 cm-1'de ölçüldü. Elde edilen değerler aşağıdaki formüle yerleştirilerek her örneğin polimerizasyon miktarı yüzdesi hesaplandı.

$$
\text { Polimerizasyon Miktarı }(\%)=100-\frac{\{\operatorname{abs}(\text { alifatik } \mathrm{C}=\mathrm{C} / \text { aromatik } \mathrm{C}=\mathrm{C}) \text { polimer }\}}{\{\operatorname{abs}(\text { alifatik } \mathrm{C}=\mathrm{C} / \text { aromatik } \mathrm{C}=\mathrm{C}) \text { monomer }\}} X 100
$$




\section{Vickers yüzey sertlik ölçümleri}

Polimerize edilen örneklerin üst ve alt yüzeylerinin mikrosertlik değerleri Vickers sertlik ölçüm cihazı (HMV Microhardness Tester, Shimadzu, Japonya) kullanılarak ölçüldü. Test esnasında 15 sn süre ile 50 gramlık yük uygulanarak cihaz çalıştııılı ve her bir örnek için ölçümler üçer kez tekrarlandı. Elde edilen ölçüm değerlerinin ortalaması o örneğin üst ve alt yüzey sertlik değeri olarak kaydedildi. Daha sonra her örneğin alt yüzey sertlik değerinin üst yüzey sertlik değerine bölümüyle herbir örneğin sertlik oranı hesaplandı.

\section{İstatistiksel analiz}

Çalışmada elde edilen bulguların istatistiksel analizi tek yönlü varyans analizi (ANOVA) ve Tukey çoklu karşılaştırmaları kullanılarak gerçekleştirildi $(\alpha=$ 0.05).

\section{BULGULAR}

\section{Is1 atış1}

Kompozit materyal içerisinde oluşan ISI artış miktarlarının çalışmada incelenen gruplar arasında farklıık gösterdiği, en fazla ısı artışının $1 \mathrm{~mm}$ 'lik dentin diski kullanılan Grup $1\left(11.4^{\circ} \mathrm{C}\right)$ görüldüğü, bunu sırasıyla kontrol grubu $\left(10.4^{\circ} \mathrm{C}\right), 2 \mathrm{~mm}$ 'lik dentin diski kullanılan Grup $2\left(7.3^{\circ} \mathrm{C}\right)$ ve $3 \mathrm{~mm}$ 'lik dentin diski kullanılan Grup $3^{\prime}$ 'ün $\left(6^{\circ} \mathrm{C}\right)$ izlediği görüldü (Tablo 1).

Tablo 1.

\section{Polimerizasyon esnasında kompozit materyal içerisinde oluşan ısı artışı}

\begin{tabular}{|cc|}
\hline Gruplar & Isı artışI ( ${ }^{\circ} \mathbf{C}$ ) \\
\hline Grup 1 & 11,4 \\
\hline Grup2 & 7,3 \\
\hline Grup3 & 6 \\
\hline Kontrol Grubu & 10,4 \\
\hline
\end{tabular}

\section{Polimerizasyon miktarına ait bulgular}

Çalışmada tüm gruplardan elde edilen polimerizasyon miktarları incelendiğinde; en yüksek polimerizasyon miktarının $1 \mathrm{~mm}$ 'lik dentin diskinin kullanıldığı Grup 1'de (\%95.16) görüldüğü, bunu kontrol grubunun (\%85.08), 2 mm'lik dentin diskinin kullanıldığı Grup 2'nin (\%79.76) ve 3 mm'lik dentin diskinin kullanıldığı Grup 3'ün (\%77) izlediği gözlendi (Şekil 1). Polimerizasyon miktarları arasındaki ilişki istatistiksel olarak değerlendirildiğinde; tüm grupların polimerizasyon miktarları arasında anlamlı farklılı̆ın olduğu tespit edildi $(p<0.05)$.

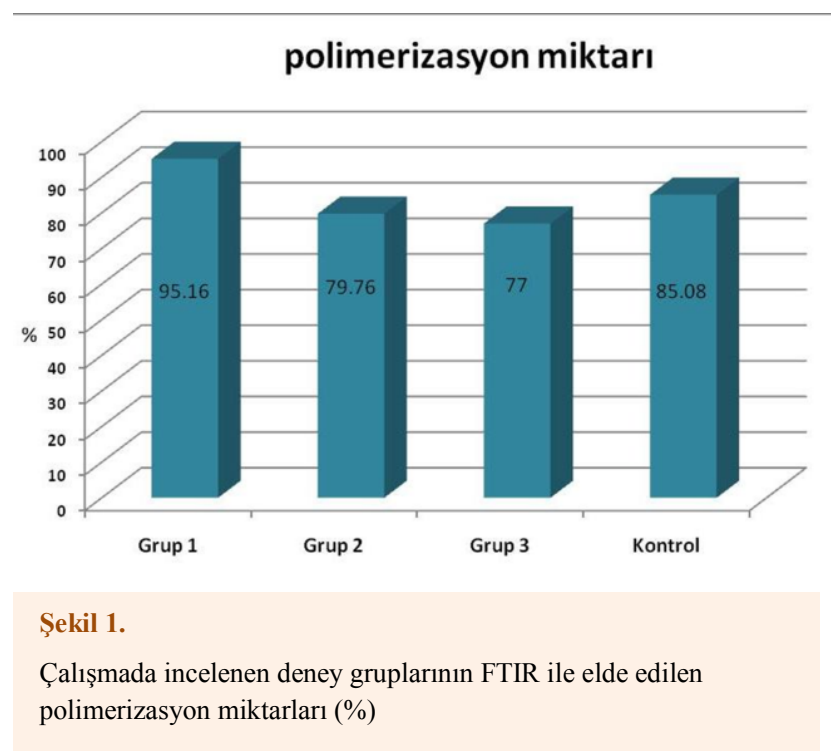

\section{Vickers yüzey sertliğine ait bulguları}

Grupların üst ve alt yüzey sertlik değerleri Şekil 2'de gösterilmektedir. Grupların üst ve alt mikrosertlik değerleri incelendiğinde; üst yüzeyde en yüksek sertlik değerleri $1 \mathrm{~mm}$ kalınlığında dentin disklerinin kullanıldığı Grup 1'de (38.65), alt yüzeyde ise 10 mm'lik camın kullanıldığı kontrol grubunda (33.08) elde edildi.

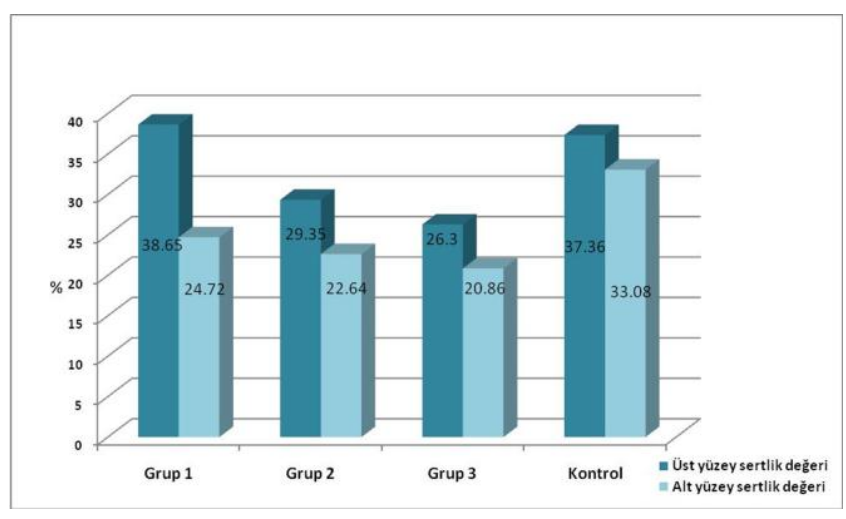

Şekil 2.

Çalışmada incelenen deney gruplarının üst ve alt yüzey mikrosertlik değerleri

Üst yüzeyde; 1 mm'lik dentin diskinin kullanıldığı Grup 1 ile $2 \mathrm{~mm}$ dentin diskinin kullanıldığı Grup 2 arasında ve $3 \mathrm{~mm}$ 'lik dentin diskinin kullanıldığı Grup 3 arasında istatistiksel olarak anlamlı farklıı̆ın olduğu tespit edildi $(p=0.000) .1$ mm'lik dentin diskinin kullanıldığı Grup 1'de elde edilen mikrosertlik değerleri ile kontrol grubunda elde edilen mikrosertlik değerleri arasında ise istatistiksel olarak anlamlı farklıı̆ı̆ı olmadığı saptandı $(p=0.787)$. 
Alt yüzeyde; kontrol grubundan elde edilen mikrosertlik değerleri ile $1 \mathrm{~mm}, 2 \mathrm{~mm}$ ve $3 \mathrm{~mm}$ 'lik dentin disklerinin kullanıldığı grupların mikrosertlik değerleri arasında anlamlı düzeyde farklılığın olduğu bulundu $(p=0.000)$. 2 mm'lik dentin diskinin kullanıldığı Grup 2 ile 1 mm'lik dentin diskinin kullanıldığı Grup 1 arasında $(p=0.207)$ ve $3 \mathrm{~mm}$ 'lik dentin diskinin kullanıldığı Grup 3 arasında $(p=0.325)$ ise anlamlı farklıığın olmadığı bulundu. 1 mm'lik dentin diskinin kullanıldığı Grup 1 ile 3 mm'lik dentin diskinin kullanıldığı Grup 3'de elde edilen alt yüzey sertlik değerleri arasında anlamlı farklılığın olduğu tespit edildi $(p=0.007)$.

Grupların alt ve üst yüzey sertlik oranları incelendiğinde ise en yüksek sertlik oranı kontrol grubunda (\%88.86) en düşük ise $1 \mathrm{~mm}$ 'lik dentin diskinin kullanıldığı Grup 1 'de (\%64.28) tespit edildiği görüldü $(p<0.05)$.

Grupların polimerizasyon miktarı ve sertlik oranları Şekil 3'te grafik olarak verilmektedir. Sadece $1 \mathrm{~mm}$ 'lik dentin diskinin kullanıldığı Grup 1'de polimerizasyon miktarı ve sertlik oranları arasında anlamlı fark olduğu gözlendiği görüldü $(p<0.05)$.

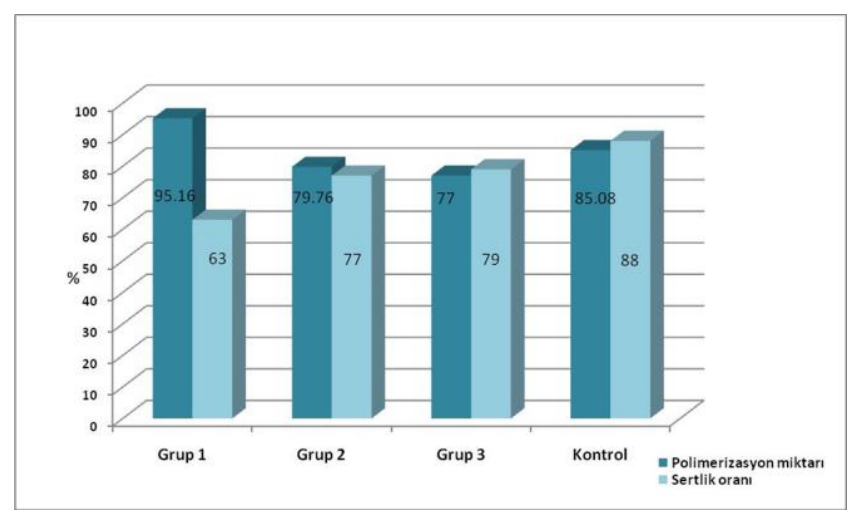

Şekil 3.

Deney gruplarının sertlik oranı ve polimerizasyon miktarları arasındaki ilișki

\section{TARTIŞMA}

Polimerizasyon büzülmesi kompozit restorasyonların klinik başarısızığının temel sebeplerindendir. Polimerizasyon büzülmesinin engellenmesi ya da azaltılması uzun ömürlü restorasyonların yapımı için oldukça önemlidir. Polimerizasyon büzülmesi kontrol edilirken kompozit rezinin polimerizasyonu da ihmal edilmemelidir. $\mathrm{Bu}$ nedenle çalışmamızda polimerizasyon büzülmesinin kontrolünde kullanılabilecek bir yöntem olan transdental ışık uygulamasının kompozit rezinin polimerizasyonu üzerine etkisi değerlendirilmiştir.
Transdental ışık uygulamasının polimerizasyon büzülmesinin olumsuz etkilerini azaltmasının kompozit materyalin restorasyon kenarlarına uyumunu arttırdığı ve bundan dolayı da kenar sızıntısının önemli ölçüde azaldığını bildiren çalışmalar mevcuttur (Bechtold ve ark 2012, Alves ve ark 2008). Ancak transdental ışık uygulamasının kompozit rezinin polimerizasyon miktarı üzerinde etkisi ile ilgili literatürde yeterli bilgi mevcut değildir. Çalışmamızda farklı kalınlıktaki dentin disklerinin üzerinden transdental olarak Işık uygulayarak polimerize edilen örneklerin polimerizasyon miktarı hem yüzey sertliği hem de FTIR ile değerlendirilmiştir. FTIR kompozit rezinin kütlesel polimerizasyonu hakkında bilgi verirken, yüzey sertliği ölçümü kompozit rezinin polimerizasyonunda ki bölgesel farklılıkları değerlendirmede etkilidir. $\mathrm{Bu}$ nedenle çalışmamızda birbirini destekleyici sonuçlar sunan iki yöntem beraber kullanılmıştır.

Transdental ışık uygulama tekniğinin çıkış noktası kompozit rezinin ışık kaynağına doğru büzüldüğü inancıdır. Ancak, Versluis ve ark. kompozit rezinin polimerizasyon büzülmesi yönünün ışık kaynağının doğrultusundan etkilenmediğini bildirmişlerdir (Versluis ve ark 1998). Yine aynı çalışmada, kompozit rezinin büzülme yönü üzerine bağlanma kuvvetleri ve kavitenin şeklinin etkisi olduğu rapor edilmiştir. Transdental ışı uygulamasının polimerizasyon büzülmesinin kontrolünde etkili olabileceği durum ise diş dokularının ışığın bir kısmını absorbe etmesine bağlı olarak ışık yoğunluğunun düşmesi, düşük yoğunluklu Işık iletimi ile başlayan kademeli polimerizasyona bağlı daha az polimerizasyon büzülmesi gözlenmesidir. Aynı durum pulse-delay ve soft-start polimerizasyon yöntemlerinde de gözlenmektedir. Yapılan çalışmalarda pulse-delay ve soft-start ışık uygulama yöntemlerinin kompozit rezinin bağlanma dayanımını ve marjinal adaptasyonu arttırdığı bildirilmiştir (Brandt ve ark 2008, SouzaJunior ve ark 2011).

Çalışmamızın bulguları polimerizasyon miktarı bakımından değerlendirildiğinde; en yüksek polimerizasyon miktarı $1 \mathrm{~mm}$ 'lik dentin diskinin kullanıldığı Grup 1'de (\%95.16) elde edildi. Bunu kontrol grubu Grup 4, 2 mm'lik dentin diskinin kullanıldığı Grup 2 ve 3 mm'lik dentin diskinin kullanıldığı Grup 3'ün izlediği gözlendi. Bu sıralama farklı kalınlıklarda dentin disklerinin kullanıldığı gruplar için beklenen şekilde ortaya çıkmıştır. Fakat $1 \mathrm{~mm}$ 'lik dentin diskinin kullanıldığı Grup 1'in polimerizasyon miktarının $10 \mathrm{~mm}$ 'lik camın kullanıldığı kontrol grubundan üstün olması şaşırtıcı bir sonuçtur. Çünkü siman camının ışığı diş dokusundan daha iyi ileteceği ve bundan 
dolayı da kontrol grubunda polimerizasyon miktarının daha fazla olacağı beklenmekteydi. Ancak bu beklenti gerçekleşmemiştir. Böyle bir bulguyu elde etmemizin değişik nedenleri olabilir. Bunlardan biri ışık cihazının ucu ile kompozit materyal arasındaki mesafedir. Yapılan çalışmalarda ışık cihazı ucu ile kompozit materyal arasındaki mesafe arttıkça polimerizasyon etkinliğinin azaldığı bildirilmiştir (Zhu ve Platt 2011, Coutinho ve ark 2013). Kontrol grubunda örnekler ile ışık cihazı arası mesafe $10 \mathrm{~mm}$ iken 1 mm'lik dentin diskinin kullanıldığı Grup 1'deki örnekler ile ışık cihazı arası mesafe $1 \mathrm{~mm}$ 'dir. Bu da ışık cihazının uç kısmı ile kompozit materyalin neredeyse temas halinde olduğunu, dolayısıyla 1 mm'lik dentin diskinin kullanıldığı Grup 1'de polimerizasyon miktarının daha fazla olmasına neden olabilir.

Mesafenin yanı sıra çalışmamızın başlangııında polimerizasyon sırasında kompozit içerisinde oluşan ıSı artışları da ölçüldü. $1 \mathrm{~mm}$ 'lik dentin diskinin kullanıldığı Grup 1'de polimerizasyon sırasında oluşan ISı artışının kontrol grubundaki örneklerden daha fazla olduğu gözlendi. Yapılan bir çalışmada polimerizasyon nedeniyle kompozit rezinin yapısında oluşan ISı artışının polimerizasyon miktarını da arttırdığı bildirilmiştir (Price ve ark 2011). Bizim çalışmamızda da örneklerde meydana gelen ISI artışındaki farklılık farklı polimerizasyon miktarı elde edilmesinin nedeni olabilir.

Çalışmamızın yüzey sertlik sonuçları değerlendirildiğinde; en yüksek üst yüzey sertlik değerleri $1 \mathrm{~mm}$ 'lik dentin diskinin kullanıldığı Grup 1 'de elde edildi. Bunu kontrol grubu, 2 mm'lik dentin diskinin kullanıldığı Grup 2 ve 3 mm'lik dentin diskinin kullanıldığı Grup 3'ün izlediği görüldü. Alt yüzeyde ise en yüksek sertlik değeri kontrol grubunda, en düşük sertlik değeri ise $3 \mathrm{~mm}$ 'lik dentin diskinin kullanıldığı Grup 3'deki örneklerde ölçüldü. Bunun siman camının ışığı geçirme miktarının diş dokusundan daha fazla olmasından dolayı oluştuğu kanısındayız. Nitekim diş dokusunun kalınlığının artmasıyla ölçülen sertlik değerlerinde azalma görülmesi bu düşüncemizi doğrulamaktadır. Ancak çalışmamızda uygulanan ışığın gücünün dentin diskleri altındaki gücü ölçülmemiştir. Bununda başka bir çalışma ile değerlendirilmesi gerekir. Ancak Alves ve arkadaşlarının kompozit örnekleri 20 sn direkt, 40 sn transdental ve $40 \mathrm{sn}$ transdental $+20 \mathrm{sn}$ direkt Işık uygulayarak polimerize ettikleri bir çalışmada da örneklerin yüzey sertliğinin 20 sn direkt ışık ile polimerize edilen örneklerde diğer gruplardan daha yüksek elde edildiği ve buna da transdental uygulama esnasında mine ve dentinden dolayı uygulanan ışığın gücünün azalmasının neden olduğu rapor edilmiştir (Alves ve ark 2008). Bu da bizim çalıșamızın sonuçlarını destekler niteliktedir.
Kompozit materyalin polimerizasyonunda üst ve alt yüzey sertlik değerlerinden ziyade sertlik oranı daha önemli bir kavramdır. Çalışmada incelediğimiz deney gruplarının sertlik oranlarının kontrol grubu $>3$ mm'lik dentin diskinin kullanıldığı Grup $3>2$ mm'lik dentin diskinin kullanıldığı Grup $2>1 \mathrm{~mm}$ 'lik dentin diskinin kullanıldığı Grup 1 şeklinde sıralandığı görülmektedir. Bu sıralama polimerizasyon miktarında tespit ettiğimiz sıralama ile aynı değildir. Özellikle kontrol grubu ve $1 \mathrm{~mm}$ 'lik dentin diskinin kullanıldığı Grup 1'in sertlik oranı ve polimerizasyon miktarı arasında bariz bir farklılık bulunmaktadır. Bu da polimerizasyon miktarının tespitinde her iki test yönteminin kullanılabileceği ancak sonuçları yorumlamanın farklı olması gerektiğini ortaya koymaktadır. Mikrosertlik ölçümleri polimerize edilen kompozit örneğin bazı noktalarında ölçülen bir değerken, polimerizasyon miktarı örneğin her noktasındaki polimerizasyon miktarını ölçen bir yöntemdir. Bu nedenle polimerizasyon miktarı hakkında genel yargıya varmak istediğimizde, FTIR testinin kullanılmasının mikrosertlik testlerine göre daha fazla fayda sağlayacağı kanısındayız.

\section{SONUÇLAR}

$\mathrm{Bu}$ çalışmanın sonuçları doğrultusunda; kompozit rezinin transdental olarak polimerize edilmesinde diş dokusu (dentin) kalınlığı arttıkça polimerizasyon miktarının azaldığı, polimerizasyon miktarının saptanmasında mikrosertlik ölçümünün tek başına kullanımının hatalı yorumlara neden olabileceği ve polimerizasyon miktarının saptanmasında FTIR testinin fayda sağlayacağı şeklinde sonuçlara varılmıştır. 


\section{Transdental ışık uygulamasının kompozit rezinlerin polimerizasyonu üzerine etkisi}

Amaç: Bu çalışmanın amacı, farklı kalınlıklarda dentin disklerinin üzerinden transdental ışık uygulanmasının kompozit rezinin polimerizasyonu üzerine etkisini Fourier Transform Infrared Spectroscopy (FTIR) ve Vickers mikrosertlik testleri ile incelemektir.

Gereç ve Yöntemler: Çürüksüz alt 3. büyük azı dişlerin bukkal yüzeylerinden 1,2 ve $3 \mathrm{~mm}$ kalınlıkta dentin diskleri hazırlandı. $5 \mathrm{~mm}$ çapında ve $2 \mathrm{~mm}$ derinliğinde teflon kalıpların içi hibrit tip bir kompozit rezin (Clearfil Majesty Esthetic) ile dolduruldu ve kompozit materyalin içerisine bir ucu dijital termometreye bağlı ısıl çift yerleştirildi. Daha sonra kompozit rezin üzerine Grup 1'de; $1 \mathrm{~mm}$ kalınlığında dentin diski, Grup 2'de; $2 \mathrm{~mm}$ kalınlığında dentin diski veya Grup 3 'de; $3 \mathrm{~mm}$ kalınlığında dentin diski yerleştirildi. Takiben kompozit rezin dentin disklerinin üzerinden LED ışık cihazı ile 40 sn ışık uygulanarak polimerize edildi. Kontrol grubunda ise kompozit rezin örnekler $10 \mathrm{~mm}$ kalınlığında bir cam üzerinden polimerize edildi. Her bir grup için toplam 10 örnek hazırlandı. Polimerizasyon sonrası dijital termometre ile ISı artışı kaydedilen örneklerin beşi yüzey sertlik testinde diğer beşi polimerizasyon miktarının tespit edilmesi amacıyla kullanıldı. Örneklerin polimerizasyon miktarı FTIR ile yüzey sertlik ölçümleri ise Vickers mikrosertlik ölçüm cihazı kullanılarak incelendi. Elde edilen bulguların istatistiksel değerlendirmesi tek yönlü varyans analizi (ANOVA) ve Tukey çoklu karşılaştırmaları kullanılarak yapıldı.

Bulgular: Çalışmada polimerizasyon sırasında kompozit materyal içerisinde oluşan ısı artış miktarının deney grupları arasında farklılık gösterdiği gözlendi. En yüksek polimerizasyon miktarı $1 \mathrm{~mm}$ 'lik dentin diskinin kullanıldığı Grup 1'de (\%95.16), en düşük polimerizasyon miktarı ise $3 \mathrm{~mm}$ 'lik dentin diskinin kullanıldığı Grup 3'de $(\% 77)$ elde edildi $(p<0.05)$. Grupların üst ve alt yüzey mikrosertlik değerleri incelendiğinde; en yüksek üst yüzey sertlik değerleri 1 mm kalınlığında dentin disklerinin kullanıldığı Grup 1 'de (38.65), alt yüzeyde 10 mm'lik camın kullanıldığı kontrol grubunda (33.08) ölçüldü.

Sonuç: Bu çalışmanın bulguları ışığında; kompozit rezinin transdental olarak polimerize edilmesinde diş doku kalınlığının polimerizasyon derecesi üzerinde etkisinin olduğu bulunmuştur.

\section{ANAHTAR KELIMELER}

Kompozit rezin, monomer değişim derecesi , transdental ışık uygulaması, yüzey sertliği,

\section{KAYNAKLAR}

Alves EB, Alonso RC, Correr GM, Correr AB, de Moraes RR, Sinhoreti MA, Correr-Sobrinho L, 2008. Transdental photo-activation technique: hardness and marginal adaptation of composite restorations using different light sources. Oper Dent 33, 421-425.

Anttila EJ, Krintilä OH, Laurila TK, Lassila LV, Vallittu PK, Hernberg RG, 2008. Evaluation of polymerization shrinkage and hydroscopic expansion of fiber-reinforced biocomposites using optical fiber Bragg grating sensors. Dent Mater 24,1720-1727.

Atai M, Watts DC, 2006. A new kinetic model for the photopolymerization shrinkage-strain of dental composites and resin-monomers. Dent Mater 22,785-791.

Bechtold J, Dos Santos PJ, Anido-Anido A, D Hipólito V, Alonso RC, D'Alpino PH, 2012. Hardness, polymerization depth, and internal adaptation of Class II silorane composite restorations as a function of polymerization protocol. Eur J Dent 6,133-140.

Brandt WC, de Moraes RR, Correr-Sobrinho L, Sinhoreti MA, Consani S, 2008. Effect of different photo-activation methods on push out force, hardness and cross-link density of resin composite restorations. Dent Mater 24,846-850.

Braga RR, Ferracane JL, 2002. Contraction stress related to degree of conversion and reaction kinetics. J Dent Res;81,114-118.

Charton C, Falk V, Marchal P, Pla F, Colon P, 2007. Influence of $\mathrm{Tg}$, viscosity and chemical structure of monomers on shrinkage stress in light-cured dimethacrylate-based dental resins. Dent Mater 23,1447-1459.

Coutinho M, Trevizam NC, Takayassu RN, Leme AA, Soares GP, 2013. Distance and protective barrier effects on the composite resin degree of conversion. Contemp Clin Dent 4,152-155.

Cunha LG, Alonso RC, Pfeifer CS, CorrerSobrinho L, Ferracane JL, Sinhoreti MA, 2008. Contraction stress and physical properties development of a resin-based composite irradiated using modulated curing methods at two C-factor levels. Dent Mater 24,392-398.

Darmani H, Al-Hiyasat AS, Milhem MM, 2007. Cytotoxicity of dental composites and their leached components. Quintessence Int 38,789795 
Ellakwa A, Cho N, Lee IB, 2007. The effect of resin matrix composition on the polymerization shrinkage and rheological properties of experimental dental composites. Dent Mater 23,1229-1235.

Ferracane JL. Buonocore Lecture 2008. Placing dental composites--a stressful experience. Oper Dent 33,247-257.

Lee MR, Cho BH, Son HH, Um CM, Lee IB, 2007. Influence of cavity dimension and restoration methods on the cusp deflection of premolars in composite restoration. Dent Mater 23,288-295.

Loguercio AD, Reis A, Ballester RY, 2004. Polymerization shrinkage: effects of constraint and filling technique in composite restorations. Dent Mater 20,236-243.

Lohbauer $U$, Rahiotis C, Krämer N, Petschelt A, Eliades G, 2005. The effect of different light-curing units on fatigue behavior and degree of conversion of a resin composite. Dent Mater 21,608-615.

Moharamzadeh K, Van Noort R, Brook IM, Scutt AM, 2007. Cytotoxicity of resin monomers on human gingival fibroblasts and $\mathrm{HaCaT}$ keratinocytes. Dent Mater 23,40-44.

Park J, Chang J, Ferracane J, Lee IB, 2008. How should composite be layered to reduce shrinkage stress: incremental or bulk filling? Dent Mater 24,1501-1505.

Pfeifer CS, Braga RR, Ferracane JL, 2006. Pulsedelay curing: influence of initial irradiance and delay time on shrinkage stress and microhardness of restorative composites. Oper Dent 31,610-615.

Price RB, Whalen JM, Price TB, Felix CM, Fahey J, 2011. The effect of specimen temperature on the polymerization of a resin-composite. Dent Mater 27,983-989.

Sharafeddin F, Sharifi E, 2013. The effect of microwave/laboratory light source postcuring technique and wet-aging on microhardness ofcomposite resin. Dent Res J 10,370-375.

Souza-Junior EJ, de Souza-Régis MR, Alonso RC, de Freitas AP, Sinhoreti MA, Cunha LG, 2011. Effect of the curing method and composite volume on marginal and internal adaptation of composite restoratives. Oper Dent 36,231-238.

Sun J, Lin-Gibson S. X-ray microcomputed tomography for measuring polymerization shrinkage of polymeric dental composites, 2008. Dent Mater 24,228-234.
Tarle Z, Knezevic A, Demoli N, Meniga A, Sutaloa J, Unterbrink G, Ristic M, Pichler G, 2006. Comparison of composite curing parameters: effects of light source and curing mode on conversion, temperature rise and polymerization shrinkage. Oper Dent 31,219226.

Versluis A, Tantbirojn D \& Douglas WH, 1998. Do Dental composites always shrink toward the light? J Dent Res 77,1435-1445.

Visvanathan $A$, llie $\mathrm{N}$, Hickel $\mathrm{R}$, Kunzelmann $\mathrm{KH}$, 2007. The influence of curing times and light curing methods on the polymerization shrinkage stress of a shrinkage-optimized composite with hybrid-type prepolymer fillers. Dent Mater 23,777-784.

Zhu S, Platt J, 2011. Curing efficiency of three different curing modes at different distances for four composites. Oper Dent 36,362-371.

Yazışma Adresi:

Insan YIKILGAN

Gazi Üniversitesi

Diş Hekimliği Fakültesi

Diş Hastalıkları ve Tedavisi AD

06510 Emek, Ankara, Türkiye

E-mail: ihsanyikilgan@gazi.edu.tr 